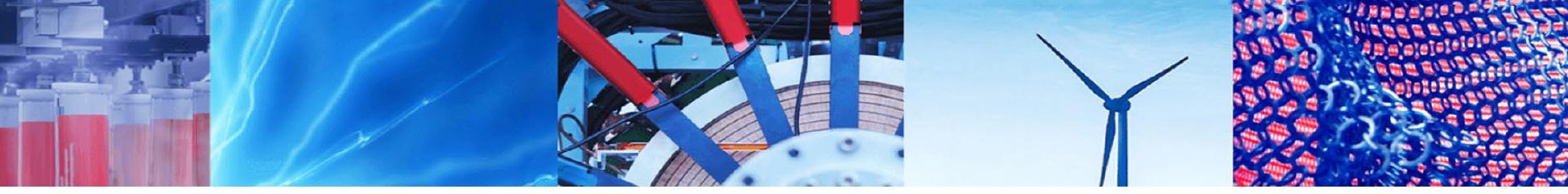

Research Article

\title{
Apparent roughness coefficient in overbank flows
}

\author{
João N. Fernandes ${ }^{1}[0$ \\ Received: 29 January 2021 / Accepted: 26 May 2021 \\ Published online: 10 June 2021 \\ (c) The Author(s) 2021 OPEN
}

\begin{abstract}
Overbank flows occur in alluvial valleys during flood events when the conveyance of main channel of rivers is exceeded. Once floodplains are inundated and the so-called compound channel flow is observed, the faster flow in the main channel interacts with the slower flow in the floodplain featuring a much more pronounced 3D flow structure compared to single channel flow. These flow mechanisms comprise a shear layer near the interface, lateral momentum transfer and strong secondary currents due to the non-isotropic turbulence. This paper starts by giving an overview of the main flow mechanisms in compound channels pointing out the importance of taking into account the apparent shear stress generated between the main channel and the floodplain flows due to the interaction of these flows. A new simple model was developed to include the apparent shear stress concept as a correction of the Manning roughness coefficient of main channel and floodplains. The proposed method for predicting stage-discharge relationships was calibrated and validated by experimental data from several compound channel facilities. A significant improvement in prediction of the compound channel conveyance in comparison with the traditional methods was achieved.
\end{abstract}

Keywords Compound channel · Overbank flows · Flood management · Roughness · Apparent shear stress

\section{Introduction}

River floods are one of the most serious disasters worldwide. Amongst the natural catastrophes, floods cause about half of all deaths [44] and a third of all economic losses [3]. The global losses due to river floods are estimated at US\$104 billion and are expected to increase with economic growth, urbanization and climatic change [5].

Moreover, floods cause not only short-term consequences such as deaths and economical and material losses, but also long-term diseases, disability and povertyrelated diseases [60]. These latter effects may be even more important than other illnesses or injuries because the psychological problems may continue for long after the water has receded [44].
Differently from other hazards, natural flooding is spread around the world and in most of the cases total protection is impossible. Even in developed countries such as France or England, river floods are responsible for dramatic losses (e.g. [6] and [50]. Taking this context into consideration, flood management plays a rather important role in urban planning and the correct modelling of inundation characteristics is of paramount importance. Flood management programs must be defined according to several concepts such as weather forecasts, flood damages, land use, floodplain characteristics and flood control structures. Amongst whole concepts needed to conduct a successful program, the delimitation of the affected area is the most prominent. In most cases, due to the extent of the river to be modelled, 1D simulations are chosen and accordingly conservation laws must be used.

$\triangle$ João N. Fernandes, jnfernandes@lnec.pt | ${ }^{1}$ Hydraulics and Environment Department, National Laboratory of Civil Engineering, Lisbon, Portugal.

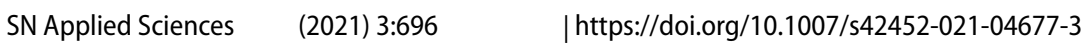


For these reasons, floods have been a concern since ancient times. Earlier civilizations were challenged to deal with flood control [19]. Hydraulic engineers must handle with the above-mentioned issues and they have to take reasonable steps to ensure the success of flood management. At the same time, engineers must promote a form of river training works progressively more sensitive to the environment [23].

The destructive damages of floods were the main reason for extensive research on this theme in the last century.

In the European context, the European Union Floods Directive (Directive 2007/60/EC) reflects the concern of the member states to handle with floods. Each state is required to assess which watercourses are at risk from flooding and to map the inundation extent. They also must take adequate and coordinate measures to reduce the flood risk.

The extent of inundation due to natural floods depends on two main factors: the hydrological regime and the river configuration. The first controls the flow discharge that drains into a certain river reach and can be evaluated from statistical models based on historical data or on the description of the processes associated with the transformation of the precipitation in runoff (e.g. [35]). The main issue of the present work is related to the second factor, namely, the influence of the cross-sectional configuration on the flow structure and therefore on the channel conveyance.

Taking as reference the extended research conducted in compound channels, i.e. when the floodplains are inundated and a complex flow structure is generated, this paper aims at reviewing the main flow mechanisms of overbank flows and consequences in terms of modelling. Moreover, following the work started in Fernandes [18], the paper presents a method to incorporate the concept of apparent shear stress (developed in the interface between the main channel and the floodplains) in the Manning roughness coefficient. In the current state, most of the used hydraulic models worldwide such as HEC-RAS or MIKE 11 do not account for this extra shear stress. With the proposed adaptation of the Manning roughness coefficient, it is expected to improve the discharge prediction of overbank flows. The calibration and validation of the proposed method are conducted taking advantage of a large dataset of experimental data obtained in compound channels.

\section{Overview of the mechanisms of overbank flows}

It is widely recognized that, when overbank flow occurs, the flow structure becomes much more complex than in a single channel [53]. The interaction between faster main channel flow and slower floodplain flow generates a shear layer in a region near the interface of these two subsections [61] and [10]. In that shear layer, the lateral momentum exchange between the main channel and the floodplains [56] and the secondary currents due to the non-isotropic turbulence [40] lead to a 3D flow structure. The momentum transfer due to the interaction between the two flows was quantified by Myers [37] who showed the importance of such phenomenon for the conveyance of compound channels.

For its wide scope, the UK project, developed in the late 1980s, with the participation of several universities and the H.R. Wallingford, financially supported by the Science and Engineering Research Council (SERC), should be mentioned. This project supported the construction, amongst others, of the Flood Channel Facility (FCF-SERC), a 10-m wide and 50-m-long compound channel [30].

Figure 1 presents the main flow mechanisms that occur in compound channels.

The flow structure in straight compound channels was experimentally and numerically studied in the last decades (e.g. [42] and [9]. Much of the research on compound channel flows has been devoted to floodplains with smooth bed (e.g. Knight and Shiono 1991 and [27]. However, as compared to the main channel, floodplains usually present a rougher bottom. They are often covered with vegetation, easily submerged during floods. The effect of submerged vegetation has been extensively studied in single channels (e.g. [32] and [41]. In compound channels, it was experimentally observed that the vegetation in the floodplains strongly affects the compound channel flow (e.g. [66]. In many studies the roughness of the floodplains does not mimic the natural environment. For instance, triangular metal meshes

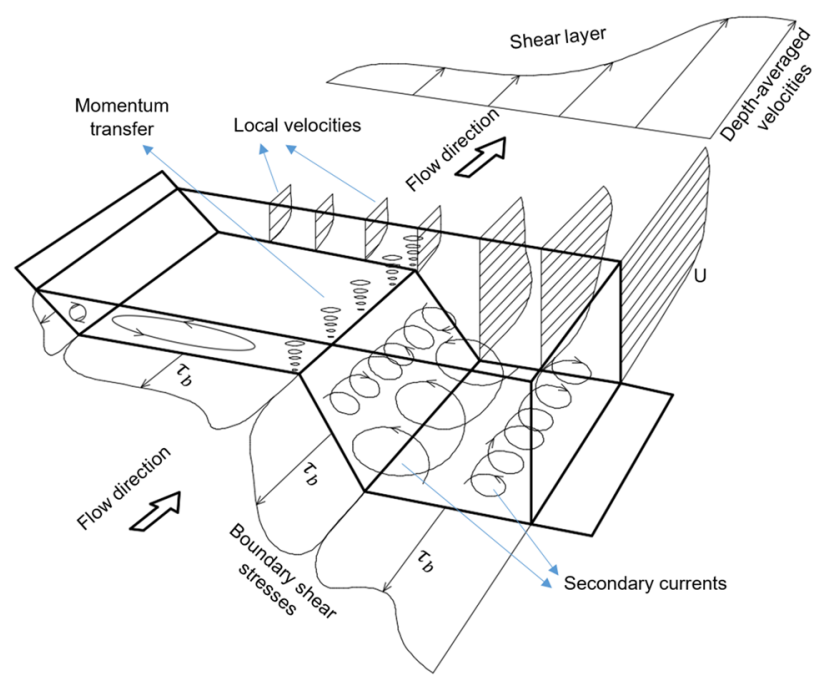

Fig. 1 Turbulent flow structure in compound channel ( adapted from [56] 
and submerged rods were used in the floodplain by Tang and Knight [59] and by Sun and Shiono [57], respectively. The specific influence in compound channel flows of submerged floodplain vegetation closer to what can be observed in the nature (e.g. grass) was experimentally studied by Pasche and Rouvé [45] and by Yang et al. [66].

Recently, Pradhan and Khatua [47] evaluated the momentum transfer coefficients of compound channels with various roughness which was able to establish a new method to compute the discharge distribution in compound channels. Due to the complexity of the flow mechanisms in compound channels, the flow discharge in these cases at a given flow depth is not as easily predicted as for single channels.

The river system cannot be perceived as limited to the watercourse. A more comprehensive concept of river may also include, for instance, riparian vegetation, wetlands, banks and ponds [39]. For hydraulic engineers, as for the society in general, the ecological protection is an increasing concern. In this framework, the ecological role and the preservation of the riparian vegetation are very much recognized as a crucial issue. As the ecological strata require diversity, a better understanding of hydrodynamics of channels with vegetation is needed. The influence of vegetation corridors on compound channel flows has been studied by Sun and Shiono [57] and by Sanjou and Nezu [51]. These studies deal with the effect of rigid rods in the floodplain edge, at the interface with the main channel, and no considerations on the influence of foliage were made. From studies in a single channel, it is well known that the contribution of vegetation to flow resistance depends strongly on the type and combination of vegetation and exhibits considerable variation in time and space (e.g. [25] and [65]. Despite that, the compound channel experiments with vegetation elements with foliage are still rare in the literature.

Due to the non-prismatic nature of rivers, non-uniform flow in compound channels is the most common situation in nature. In the last decades, several geometries were investigated including skewed compound channels, converging or diverging floodplains (Bousmar et al. 2004 and [12] and meandering channels [46]. In prismatic geometries, the non-uniform flow may be a consequence of: (i) a backwater effect caused by the downstream boundary condition, under subcritical flow, (ii) a change in the water depth caused by the rising or declining phases of a hydrogram, or (iii) a disequilibrium in the upstream velocity distribution between the main channel and the floodplains. Non-uniform flow in compound channels induces the mass transfer between main channel and floodplains. Comparing to uniform flow, it was observed that boundary shear stress, turbulence and secondary flows are strongly affected by the non-uniformity [62].

\section{Computation of compound channel conveyance}

\subsection{Traditional method}

The traditional procedure to compute the flow discharge in straight compound channels is the divided channel method (DCM). It proposes the conceptual division of the compound channel following vertical, horizontal or diagonal lines dividing main channel and lateral floodplains. Most hydraulic models (such as HEC-RAS and MIKE 11) use vertical dividing lines. The total discharge, $Q$, is then evaluated by the sum of the subsection discharges. Using Manning-Strickler equation, this method is described by:

$Q=\sum_{i} Q_{i}=\sum_{i} \frac{A_{i} R_{i}^{2 / 3}}{n_{i}} s_{0}^{1 / 2}$

where $A$ is the area, $R$ is the hydraulic radius, $n$ is the Manning roughness coefficient for each subsection, $i$ (i.e. main channel and floodplain) and $s_{o}$ is the streamwise slope.

For the DCM, the diagonal division of the compound channel is preferred for the total discharge evaluation, whereas no division gave accurate results for the subsection discharges (e.g. [29] and [1]. The vertical division tends to under predict the floodplain discharge and to over predict the main channel and the total discharges. This inaccuracy is increased for wider and rougher floodplains [63].

Bhowmik and Demissie [4] carried out field measurements in American rivers with a compound section configuration. They separated the effects of the interaction between the main channel and the floodplain flows according to the relative depth (relation of the floodplain and main channel flow depths). For small relative depths, due to the vegetation in the floodplains, in some cases the discharge in the floodplains is extremely low and they can be considered as a storage area. For higher relative depths, the floodplains contribute effectively for the total discharge.

Seckin [52] applied four prediction methods to laboratory experimental data with fixed and mobile beds in the main channel. As two methods included the effects of the interaction between the main channel and the floodplain flows, they gave better results than the traditional methods. Despite that, absolute error between the calculated and the observed discharge of approximately $10 \%$ was found. With a mobile bed in the main channel, all the methods failed to accurately predict flow discharge. 
Hin et al. [20] presented a field study including the stage-discharge relation and bed roughness for three Malaysian rivers with overbank flow. The apparent shear between flows in the main channel and in the floodplains was quantified in terms of an apparent friction factor that was found to be many times greater than the averaged friction factor associated with boundary shear stress. For the three rivers, the DCM with vertical division lines between the subsections led to an averaged over estimation of the total discharge of about $20 \%$.

In a fluvial restoration project, MacWilliams et al. [34] evaluated the effects of a constructed compound channel in the velocity and in the boundary shear stress. Analysing post-project surveys, the authors made clear that the compound channel design reduced the channel incision while achieving the specific geomorphic, ecological and flood conveyance objectives of the restoration project. The authors found that the use of 1D model HEC-RAS (i.e. DCM with vertical divisions) was of very limited value in assessing changes in channel shear stress, resulting from the construction of a compound channel on an incised stream.

\subsection{Apparent shear stress}

To account for the additional head loss generated by the interactions between the flows in the main channel and in the floodplains, the apparent shear stress method, ASSM [36] and [8], proposes the inclusion of an additional shear stress, $\tau_{a}$, acting on the vertical interface between the main channel and the floodplains. The total discharge may be calculated by the sum of the subsections discharges assuming this additional shear stress:
$D C M$, the flow discharge of the floodplains is increased because of the influence of the faster flow of the main channel. In the opposite way, the main channel flow discharge is reduced. Globally, the inclusion of the apparent shear stress leads to a decrease of the flow discharge in the whole compound cross section.

This apparent shear stress, $\tau_{a}$, may be obtained by the integration, over the floodplain or the main channel widths, of the depth-averaged momentum equation in the streamwise direction for uniform flow. Under uniform flow, neglecting the dispersion term and the lateral variation of the water depth (see e.g. [56]:

$-\frac{1}{H}\left(\rho g h s_{0}-\tau_{0}\right)=\frac{\partial \tau_{x y}^{d}}{\partial y}-\rho \frac{\partial V U}{\partial y}$

where superscript $d$ means a depth-averaged value and $\tau_{x y}$ is the Reynolds shear stress.

Integrating this equation over the floodplain width, from lateral position $B_{m c}$ to $B$ (see Fig. 2 for geometrical parameters):

$\int_{B_{m c}}^{B}\left[-\frac{1}{H}\left(\rho g H s_{0}-\tau_{0}\right)\right] d y=\int_{B_{m c}}^{B}\left[\frac{\partial \tau_{x y}^{d}}{\partial y}\right] d y-\int_{B_{m c}}^{B}\left[\rho \frac{\partial V U}{\partial y}\right] d y$

The right-hand side of Eq. (4) is denominated apparent shear stress. In the vertical interface between the main channel and the floodplain it takes the following value:

$\tau_{a}=-\left.\tau_{x y}^{d}\right|_{B_{m c}}+\left.\rho U V\right|_{B_{m c}}$

$Q=Q_{m c}+Q_{f p}=A_{m c} \frac{R_{m c}{ }^{2 / 3}}{n_{m c}} S_{0}^{1 / 2} \sqrt{1-\left(\frac{N_{f p} \tau_{a} h_{f p}}{\rho g A_{m c} S_{0}}\right)}+A_{f p} \frac{R_{f p}{ }^{2 / 3}}{n_{f p}} S_{0}^{1 / 2} \sqrt{1+\left(\frac{\tau_{a} h_{f p}}{\rho g A_{f p} S_{0}}\right)}$

where $h$ is the flow depth, $N_{f p}$ the number of floodplains ( 1 or 2$), \rho$ is the fluid density, $g$ is the gravity acceleration and subscripts $f p$ and $m c$ stand for floodplain and main channel, respectively. When compared to the results of
Equation (5) shows that the apparent shear stress has two distinct components: one arising from turbulence and the other from secondary currents [56]. The ASSM assumes that $\tau_{a}$ can be modelled as a function of the
$B$

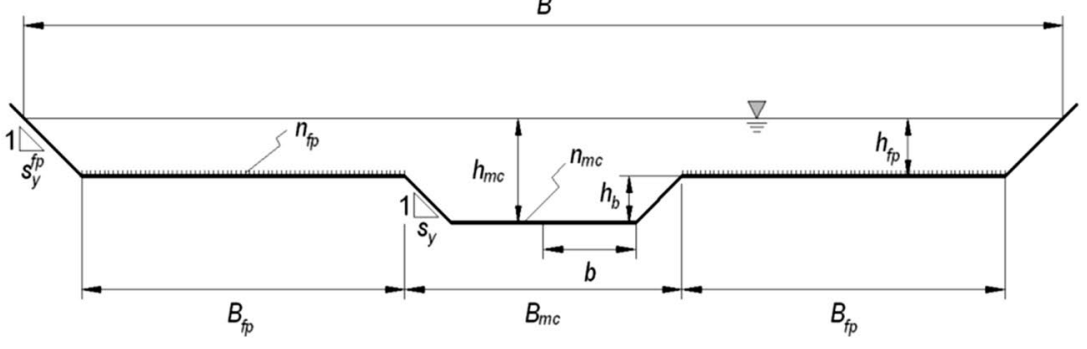

B

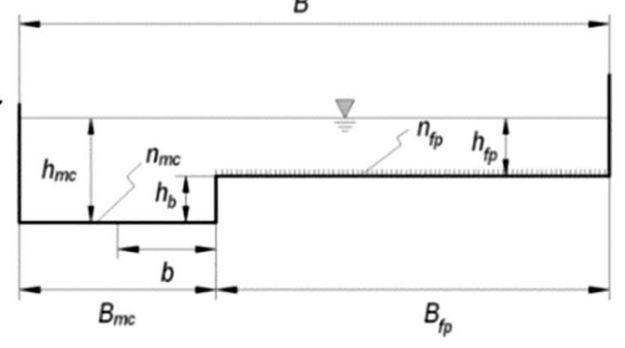

Fig. 2 Schematic cross section of a a symmetric and $\mathbf{b}$ asymmetric compound channel 
channel characteristics (such as geometrical parameters or roughness parameters).

Taking into account a momentum balance in each subsection and the boundary shear stress measurements under uniform flow, Myers [37] quantified the apparent shear stress in the vertical interface of the subsections. Since then several researchers tried to model it, following a similar empirical procedure. Based on the Prandtl's mixing length theory, Ervine and Baird [14] suggested the dependency of the apparent shear stress on the square of the velocity gradient between the flows in each subsection. Prinos and Townsend [48] obtained a solution for the apparent shear stress using a multiple linear regression to their experimental data in symmetric compound channel. Using the data of FCF-SERC, Wormleaton and Merret [63] proposed an empirical formula to estimate the apparent shear stress in straight compound channels. Christodoulou [11] proposed a simple and dimensionally sound formula that suggests that the apparent shear stress that depends on the ratio between the floodplain and the main channel widths. Huthoff et al. [22] developed a new equation for the apparent shear stress in the interface based on the difference between the squared average velocities in the main channel and in the floodplain.

For its wide range of geometries, geometrical scales and roughness distributions, it is important to highlight the equation from Moreta and Martin-Vide [36]. These authors propose two equations, separating the prediction of the apparent shear stress into small- and large-scale channels. Fernandes et al. [15] validated this equation with experimental data and the authors proposed the consideration of the equation for large-scale channels for whole conditions. The need to divide the data into two sub-data was assigned to establishment of uniform flow conditions in small-scale channels with single water supply for both main channel and floodplain.

It is quite common to consider that although the empirical equations for the apparent shear stress fit quite well to the data series for which they are developed, a more general implementation should be carefully regarded [28].

\section{Proposed method}

The proposed method aims at using an extensive compound channel flows data to evaluate the correction of the Manning roughness coefficient in the main channel and in the floodplains to account for the apparent shear stress generated in the interface of these two subsections.

The dataset used to calibrate and validate the proposed method was gathered in Fernandes et al. [17]. The schematic representations of symmetrical and asymmetrical compound channels with vertical and inclined main channel sidewalls and the main cross-sectional geometrical parameters are presented in Fig. 2 .

The experimental data are presented in Table 1, where they are split into four groups depending on the geometry and on the roughness of the floodplains. All experiments were conducted under uniform flow.

Data comprise relatively small laboratory compound channels as well as data from the large-scale FCF-SERC. Different combinations of symmetry and inclination, such as symmetrical channel with vertical walls, are covered. Some of the data from FCF-SERC were recovered from the large database published on the website of the University of Birmingham (identified as flow database FCF-SERC). In Table $1, N$ stands for the number of experiments, $h_{r}$ is the relative flow depth, i.e. the relation between the floodplain and the main channel flow depths, and $s_{y}$ and $s_{y}{ }^{f p}$ stand for the transverse slopes of the main channel and the floodplain(s) banks (1: $s_{y}$ and $1: s_{y}{ }^{f p}$, vertical: horizontal).

This relative depth is rather important when referring compound channel as it gives a clue to the interaction of the flows. For low relative depths, typically $h_{r}<0.3$, this interaction can be rather important and for higher relative depths, the compound channel effects vanish, and flow mechanisms are close to what can be observed in a single channel.

In the total of 710 flow cases used in this study, there is a preponderance of experiments that were performed in symmetric compound channels ( 284 with smooth floodplains and 181 with rough floodplains). The remaining 245 flow cases refer to asymmetric channels: 164 with rough floodplains and 81 with smooth floodplains.

Besides these laboratory data, field data were collected from Singh and Tang $[54,55]$ and associated supplementary data. These river datasets refer to rivers Batu, Severn and Main and were used only in the validation process.

It is rather important to point out that the value of the Manning roughness coefficient is available for all experiments. The experimental data comprise the stage-discharge relation for whole flow cases and the subsection discharge (main channel and floodplain) was available for approximately $1 / 3$ of the flow cases. In some cases, this coefficient is different for main channel and floodplains as different bed materials were used. With these data, the calculation of the flow discharge in each subsection with DCM is quite straightforward (cf. Equation 1).

Depending on the availability of the subsection discharge, the complete database was divided into:

- Dataset $A$ (used for calibration) data with experimental measurement of the flow discharge in the main channel and floodplain and

- Dataset B (used for validation) Experimental data with measurement of only total discharge. 
Table 1 Summary of the experimental data

\begin{tabular}{|c|c|c|c|c|c|c|c|c|c|}
\hline References & $B_{f p}(\mathrm{~m})$ & $B_{m c}(\mathrm{~m})$ & $h_{b}(\mathrm{~m})$ & $s_{y}(-)$ & $s_{y}^{f p}(-)$ & $s_{0}\left(\times 10^{-3}\right)$ & $h_{r}(-)$ & $N$ & Dataset \\
\hline \multicolumn{10}{|c|}{ Symmetric geometry and smooth floodplains (284 experiments) } \\
\hline Knight and Demetriou [31] & $0.076-0.229$ & 0.152 & 0.076 & 0 & 0 & 0.96 & $0.108-0.503$ & 18 & A \\
\hline Myers [38] & $0.18-0.3$ & 0.16 & $0.08-0.12$ & 0 & 0 & 0.93 & $0.067-0.535$ & 33 & A \\
\hline James and Brown [24] & 0.572 & 0.279 & 0.051 & 1 & 1 & $1-3$ & $0.002-0.311$ & 50 & B \\
\hline James and Brown [24] & 0.191 & 0.279 & 0.051 & 1 & 1 & $1-3$ & $0.008-0.383$ & 42 & B \\
\hline James and Brown [24] & 0.191 & 0.279 & 0.051 & 1 & 1 & $1-3$ & $0.020-0.423$ & 38 & B \\
\hline James and Brown [24] & 0.502 & 0.381 & 0.069 & 1 & 1 & $1-3$ & $0.011-0.315$ & 19 & $\mathrm{~B}$ \\
\hline Noutsopoulos and Hadjipanos [43] & $0.225-0.425$ & 0.150 & 0.075 & 0 & 0 & 1.5 & $0.187-0.479$ & 16 & $\mathrm{~B}$ \\
\hline Prinos and Townsend [48] & 0.381 & $0.244-0.367$ & 0.102 & 0.5 & 0 & 0.3 & $0.089-0.329$ & 10 & B \\
\hline Wormleaton and Merret [63] & 2.25 & 1.80 & 0.15 & 1 & 0 & 1.03 & $0.041-0.500$ & 23 & A \\
\hline Flow database FCF s8 & 2.25 & 1.80 & 0.15 & 0 & 0 & 1.03 & $0.050-0.500$ & 8 & A \\
\hline Flow database FCF s10 & 2.25 & 2.10 & 0.15 & 2 & 0 & 1.03 & $0.051-0.464$ & 8 & $A$ \\
\hline Atabay [2] & 0.407 & 0.398 & 0.05 & 0 & 0 & 2.02 & $0.071-0.490$ & 13 & $A$ \\
\hline Fernandes et al. [16] & 0.70 & 0.60 & 0.10 & 1 & 0 & 1.1 & $0.100-0.380$ & 6 & A \\
\hline \multicolumn{10}{|c|}{ Symmetric geometry and rough floodplains (181 experiments) } \\
\hline James and Brown [24] T13 & 0.502 & 0.381 & 0.069 & 1 & 1 & $1-3$ & $0.044-0.385$ & 18 & B \\
\hline Wormleaton et al. [64] & 0.46 & 0.288 & 0.12 & 0 & 0 & $0.4-1.8$ & $0.111-0.429$ & 40 & B \\
\hline Knight and Hamed [29] & $0.076-0.229$ & 0.152 & 0.076 & 0 & 0 & 0.97 & $0.104-0.518$ & 48 & $24 \mathrm{~A} / 24 \mathrm{~B}$ \\
\hline Prinos and Townsend [48] & 0.381 & $0.244-0.367$ & 0.102 & 0.5 & 0 & 0.3 & $0.089-0.329$ & 30 & B \\
\hline Wormleaton and Merret [63] & 2.25 & 1.80 & 0.15 & 1 & 0 & 1.03 & $0.038-0.505$ & 8 & A \\
\hline Hu and Guo [21] & 0.35 & 0.30 & 0.06 & 0 & 0 & 1.0 & $0.341-0.528$ & 5 & B \\
\hline Fernandes et al. [16] & 0.70 & 0.60 & 0.10 & 1 & 0 & 1.1 & $0.150-0.300$ & 3 & A \\
\hline Tang [58] & 0.41 & 0.398 & 0.05 & 0 & 0 & $2.0-2.1$ & $0.172-0.603$ & 29 & $A$ \\
\hline \multicolumn{10}{|c|}{ Asymmetric geometry and smooth floodplains (81 experiments) } \\
\hline Myers [37] & 0.356 & 0.254 & 0.102 & 0 & 0 & 0.26455 & $0.086-0.394$ & 10 & B \\
\hline Flow database FCF s6 & 2.25 & 1.8 & 0.15 & 1 & 0 & 1.03 & $0.052-0.503$ & 8 & A \\
\hline Atabay [2] & 0.407 & 0.398 & 0.05 & 0 & 0 & 2.04 & $0.165-0.499$ & 8 & B \\
\hline Bousmar and Zech [7] & 0.40 & 0.40 & 0.05 & 0 & 0 & 0.9 & $0.081-0.366$ & 4 & B \\
\hline Proust [49] & 0.80 & 0.40 & 0.05 & 0 & 0 & 1.8 & $0.219-0.412$ & 3 & $A$ \\
\hline Data from Macintosh [33]* & $0.128-0.293$ & $0.515-0.625$ & 0.055 & 0 & 0 & 1 & $0.172-0.515$ & 12 & B \\
\hline Joo and Seng [26] & 0.20 & 0.05 & 0.05 & 0 & 0 & 10.3 & $0.1844-0.2607$ & 7 & B \\
\hline Al-Khatib et al. [1] & $0.10-0.20$ & $0.10-0.20$ & $0.02-0.06$ & 0 & 0 & 10.3 & $0.1892-0.8182$ & 29 & B \\
\hline \multicolumn{10}{|c|}{ Asymmetric geometry and rough floodplains (164 experiments) } \\
\hline James and Brown [24] & 0.1905 & 0.279 & 0.051 & 1 & 1 & $1-3$ & $0.002-0.444$ & 36 & B \\
\hline James and Brown [24] & 0.368 & 0.279 & 0.051 & 1 & 1 & $1-3$ & $0.048-0.413$ & 43 & B \\
\hline James and Brown [24] & 0.502 & 0.279 & 0.051 & 1 & 1 & $1-3$ & $0.008-0.378$ & 29 & B \\
\hline Data from Macintosh [33]* & $0.128-0.293$ & $0.515-0.625$ & 0.055 & 0 & 0 & 1 & $0.167-0.507$ & 48 & B \\
\hline Joo and Seng [26] & 0.20 & 0.05 & 0.05 & 0 & 0 & 10.3 & $0.2068-0.3417$ & 8 & B \\
\hline \multicolumn{10}{|l|}{ Field data ( 24 cases) } \\
\hline River Batu* & 2.2 & 2.5 & 1.544 & 3.24 & 0 & 1.6 & $0.0013-0.3110$ & 8 & B \\
\hline River Severn* & 20.8 & 2.5 & 5.9 & 6.905 & - & 0.2 & $0.0309-0.2441$ & 6 & B \\
\hline River Main* & 4.5 & 2.5 & 0.92 & 6.911 & - & 0.3 & $0.0417-0.4860$ & 10 & B \\
\hline
\end{tabular}

* These data were obtained from Singh and Tang [54, 55]

Note that experimental data from Dataset $A$ was not included in Dataset $B$, i.e. these two groups do not intersect. For each reference, last column of Table 1 presents the corresponding dataset.
The proposed method aims at easily accounting for the effects of the apparent shear stress in the interface of main channel and floodplain flows is based on the experimental observation that this shear stress leads 
to an increase of the flow discharge in the floodplains and reduces the main channel and total flow discharge. Therefore, even if the bed material corresponds to a certain Manning roughness coefficient, when overbank flow occurs, the method proposes to affect this coefficient by different factors, $\varphi$, to account for this effect.

The proposed method was calibrated and validated according to the following steps:

(i) Evaluation of the flow discharge in the main channel and floodplain by the divided channel method (Eq. 1) using the experiments of Dataset A (those with complete discharge data for each subsection), with vertical division lines and the Manning roughness coefficient corresponding to the channel bed material;

(ii) Calculation, for each flow case of Dataset A, of the correction factors associated with Manning roughness coefficients for the main channel, $\varphi_{m c^{\prime}}$ and for the floodplain, $\varphi_{f p}$, using the following equations:

$Q_{m c}=A_{m c} \frac{R_{m c}{ }^{2 / 3}}{\varphi_{m c} n_{m c}} s_{0}^{1 / 2}$

$Q_{f p}=A_{f p} \frac{R_{f p}^{2 / 3}}{\varphi_{f p} n_{f p}} s_{0}^{1 / 2}$

and using the experimentally measured flow discharges in the main channel and in the floodplains, $Q_{m c}$ and $Q_{f p}$.

(iii) Validation of the method by comparing the experimental flow discharges of flow cases from Dataset $B$ with the flow discharges calculated assuming the average correction coefficients for each subsection calculated in (ii) and the total flow discharge by the sum of the subsection discharges.

The Dataset A was used to calibrate the correction factors for the Manning roughness coefficient in the floodplain and in the main channel. A total of 184 experiments collected from the literature were included in this dataset.

Figure 3 presents the results for the correction factors compared to the relative depth of each experiment.

Despite the stronger shear layer generated by lower relative depths, it was not observed a strong correlation between this depth and the correction coefficients. The same type of correlation was tried for the relationship between the correction factors with other characteristics of the compound channel like the geometrical dimensions or the aspect ratio or cross-section shape. As the

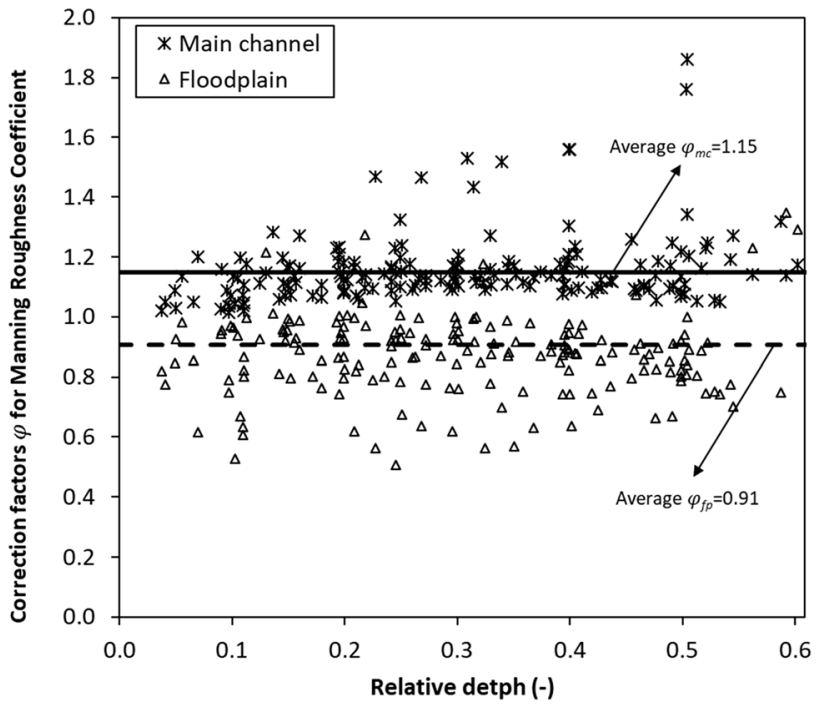

Fig. 3 Correction factors for the Manning roughness coefficients for main channel and floodplain

results did not reveal strong correlations with any compound channel characteristic, it was decided to assume constant correction coefficients. Their values, obtained by averaging all values, were $\varphi_{m c}=1.15$ and $\varphi_{f p}=0.91$.

The validation Dataset $B$ was then used to check the advantage of considering these coefficients in comparison with the results of DCM and of method developed by Moreta and Vide [36]. The results are presented in Fig. 4 for the laboratory experiments of Dataset $B$.

The deviation, $\Delta$, between each pair of calculated and measured discharge was calculated for both methods using the following equation:

$\Delta=100 \times\left(Q_{c}-Q_{m}\right) / Q_{m}$

where subscripts $m$ and $c$ stand for, respectively, the measured and the calculated flow discharge.

In Fig. 4, dashed lines correspond to a band $\pm 20 \%$ deviation.

The results of the deviations obtained with Dataset $B$ are presented in Table 2.

The results show that a global improvement in the flow discharge prediction was achieved by the simple change of the Manning roughness coefficients, i.e. by following the proposed method. By analysing the deviations per type of channel, it becomes clear that this improvement is much more evident in smooth floodplains. This result is linked with the number of experiments considered for the calibration of the correction factors (see column Dataset in Table 1). 

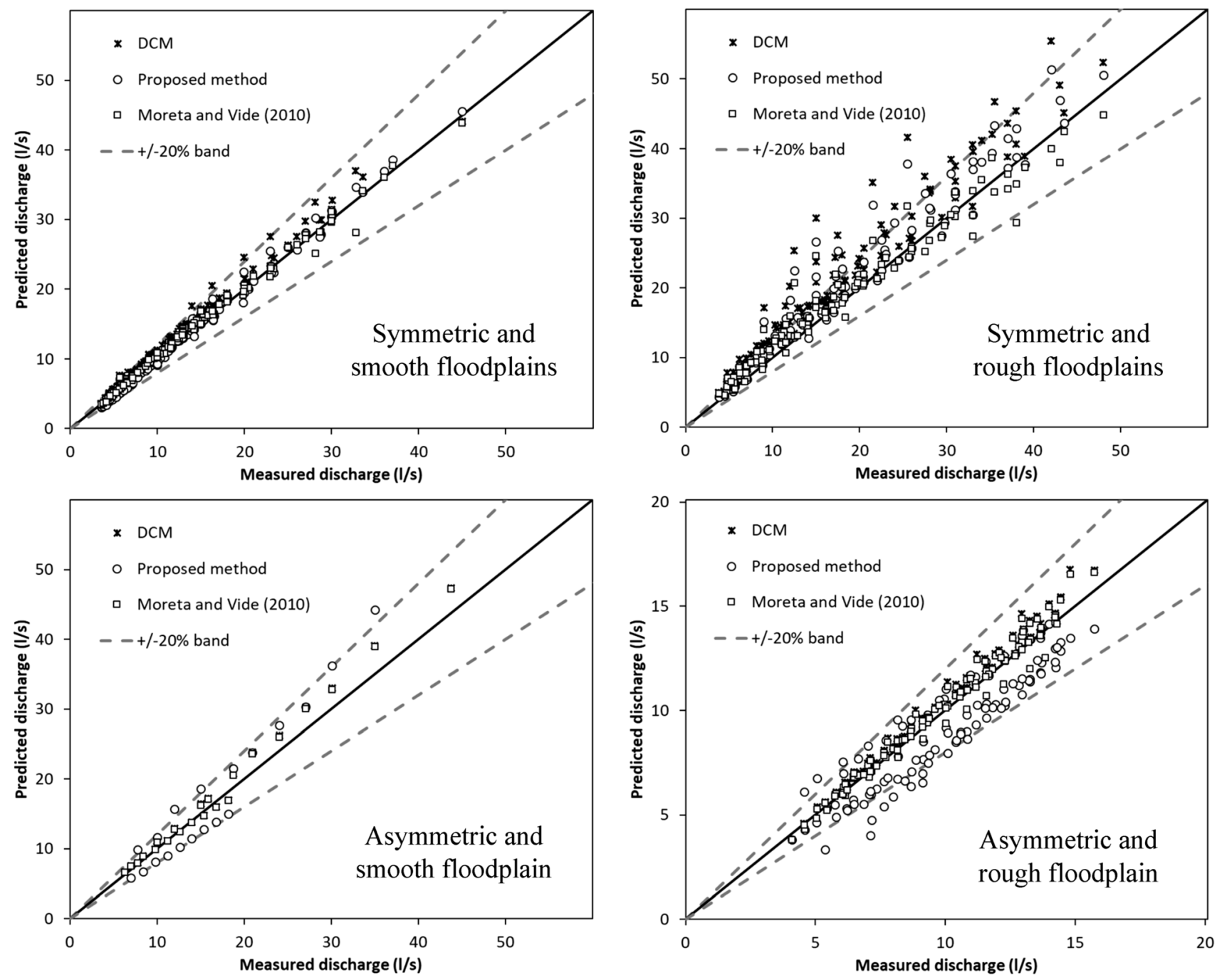

Fig. 4 Results of the three methods for laboratory experiments of Dataset B

Table 2 Deviations obtained by the three methods

\begin{tabular}{lccllc}
\hline Method & $\begin{array}{l}\text { Symmetric } \\
\text { smooth fp }\end{array}$ & $\begin{array}{l}\text { Symmetric } \\
\text { rough fp }\end{array}$ & $\begin{array}{l}\text { Asymmetric } \\
\text { smooth fp }\end{array}$ & $\begin{array}{l}\text { Asymmetric } \\
\text { rough fp }\end{array}$ & River dataset \\
\hline DCM & 8.50 & 25.18 & 7.27 & 1.37 & 19.81 \\
Moreta and Vide [36] & 3.74 & 8.49 & 6.66 & -0.24 & 14.35 \\
Proposed Method & -3.37 & 14.22 & 2.78 & -8.31 & 8.45 \\
\hline
\end{tabular}

\section{Concluding remarks}

In terms of natural hazards, floods are one of the most problematic tragedies generating high number of deaths and economic losses on both short and long terms. In natural rivers and particularly in the alluvial downstream reaches, compound channels configurations are rather common. In these cases, complex flow structure is observed and important interactions between main channel and lateral floodplains flows must be accounted for when dealing with modelling inundated areas.

Under these conditions the subsection and the total flow discharge are not as easily predicted as for single channels. To overcome with this difficulty, a new and simple method was proposed to evaluate this flow discharge in compound channels by including the concept of apparent shear stress as a correction of the Manning roughness coefficients. A considerable improvement in the traditional method was obtained with the use of simple average 
correction factors for the Manning coefficients in the main channel and floodplains for smooth floodplains. Following these promising results, further research will be conducted to understand the influence of the characteristics of the compound channel in the correction factors.

Acknowledgements The work presented in this paper was started in Fernandes (2020). The author acknowledges the financial support to the Project MixFluv-Mixing Layers in fluvial systems (reference Lisboa-01-0145-Feder-031771) by FEDER and Science and Technology Foundation.

Data availability The data that support the findings of this study are available from the corresponding author, J.N.F., upon reasonable request.

\section{Declarations}

Conflict of interest The corresponding author states that there is no conflict of interest.

Open Access This article is licensed under a Creative Commons Attribution 4.0 International License, which permits use, sharing, adaptation, distribution and reproduction in any medium or format, as long as you give appropriate credit to the original author(s) and the source, provide a link to the Creative Commons licence, and indicate if changes were made. The images or other third party material in this article are included in the article's Creative Commons licence, unless indicated otherwise in a credit line to the material. If material is not included in the article's Creative Commons licence and your intended use is not permitted by statutory regulation or exceeds the permitted use, you will need to obtain permission directly from the copyright holder. To view a copy of this licence, visit http://creativecommons. org/licenses/by/4.0/.

\section{References}

1. Al-Khatib I, Dweik A, Gogus M (2012) Evaluation of separate channel methods for discharge computation in asymmetric compound channels. Flow Meas Instrum 24:19-25. https://doi. org/10.1016/j.flowmeasinst.2012.02.004

2. Atabay S (2001) Stage-discharge, resistance and sediment transport relationships for flow in straight compound channels, PhD thesis, University of Birmingham, U.K.

3. Berz G (2000) Flood disasters: lessons from the past - worries for the future, keynote in proceedings of the 28th Congress of IAHR, Post congress volume, Graz, Austria

4. Bhowmik N, Demissie M (1982) Carrying capacity of flood plains. J Hydraul Div 108(3):443-452

5. Blöschl G, Hall J, Viglione A et al (2019) Changing climate both increases and decreases European river floods. Nature 573:108111. https://doi.org/10.1038/s41586-019-1495-6

6. Boudou M, Lang M, Vinet F, Cœur D (2016) Comparative hazard analysis of processes leading to remarkable flash floods (France, 1930-1999). J Hydrol 541:533-552

7. Bousmar D, Zech Y (2004) Velocity distribution in non-prismatic compound channels. Proc Inst Civil Eng Water Manag 157(2):99-108

8. Bousmar D, Mathurin B, Fernandes JN, Filonovich M, Hazlewood C, Huthoff F, Leal JB, Paquier A. Proust S (2016) Uniform flow in prismatic compound channel: benchmarking numerical models. River Flow 2016, 11/07/2016-15/07/2016, Saint Louis, USA. p. 272-280, $9 \mathrm{p}$

9. Brito M, Fernandes J, Leal JB (2016) Porous media approach for RANS simulation of compound open-channel flows with submerged vegetated floodplains. Environ Fluid Mech 16(6):12471266. https://doi.org/10.1007/s10652-016-9481-0

10. Costabile P, Macchione F, Natale L, Petaccia G (2015) Flood mapping using LIDAR DEM. Limitations of the 1-D modeling highlighted by the 2-D approach. Nat Hazards 77(1):181-204

11. Christodoulou GC (1992) Apparent shear stress in smooth compound channels. Water Resour Manage 6(3):235-247

12. Das BS, Khatua KK (2018) Numerical method to compute water surface profile for converging compound channel. Arab J Sci Eng 43(10):5349-5364

13. Directive $2007 / 60 / E C$ of the European Parliament and of the Council of 23 October 2007 on the assessment and management of flood risks

14. Ervine DA, Baird JI (1982) Rating curves for rivers with overbank flow. Proc Inst Civil Eng London 73(2):465-472

15. Fernandes, JN, Leal JB, Cardoso AH (2011) Discussion of: apparent friction coefficient in straight compound channels" by Moreta PJM, Martin-Vide JP (2010), J Hydraul Res, vol. 48 (2), 169-177. J Hydraul Res, vol. 49 (6), 836-839

16. Fernandes JN, Leal J, Cardoso AH (2014) Improvement of the lateral distribution method based on the mixing layer theory. Adv Water Res 69:159-167

17. Fernandes JN, Leal J, Cardoso AH (2015) Assessment of stagedischarge predictors for compound open-channels. Flow Meas Instrum 45:62-67

18. Fernandes JN (2020) Incorporating apparent shear stress in the roughness to improve the discharge prediction in overbank flows. In: Fernandes F, Malheiro A, Chaminé H (eds) Advances in natural hazards and hydrological risks: meeting the challenge. Advances in science, technology \& innovation. Springer, New York

19. Garde RJ, Ranga Raju KG (1985) Mechanics of sediment transportation and alluvial stream problems, 2nd edn. Willey Eastern Limited, New Jersey

20. Hin LS, Besaih N, Ling LP, Ghani A, Seng MY (2008) Determination of apparent and composite friction factors for flooded equatorial natural rivers. Int J River Basin Manag 6(1):3-12

21. Hu C, Ji Z, Guo Q (2010) Flow movement and sediment transport in compound channels. J Hydraul Res 48(1):23-32

22. Huthoff F, Roos PC, Augustijn DCM, Hulscher S (2008) Interacting divided channel method for compound channel flow. J Hydraul Eng 134(8):1158-1165

23. Ikeda S, McEwan IK (2009) Flow and sediment transport in compound channels: the experiences of Japanese and UK research. International Association for Hydraulic Research, Monograph Series, Balkema

24. James M, Brown BJ (1977) Geometric parameters that influence floodplain flow, Research report H-77-I, U.S. Army Engineer Waterways Experiment Station, Hydraulic Laboratory, Vicksburg, Missouri, U.S.A., $141 \mathrm{p}$

25. Järvelä J (2004) Determination of flow resistance caused by non-submerged woody vegetation. Int J River Basin Manag 2(1):61-70

26. Joo CBH, Seng DMY (2008) Study of flow in a non-symmetrical compound channel with rough flood plain. J Inst Eng 69(2):18-26

27. Keshavarzi A, Hamidifar $\mathrm{H}$ (2018) Kinetic energy and momentum correction coefficients in compound open channels. Nat Hazards 92(3):1859-1869. https://doi.org/10.1007/ s11069-018-3285-0 
28. Knight DW (2001) Conveyance in 1D river models - Annex of Scoping study on reducing uncertainty in river flood conveyance". R\&D Technical Report to DEFRA/Environment Agency

29. Knight DW, Hamed ME (1984) Boundary shear in symmetrical compound channels. J Hydraul Eng 110(10):1412-1430

30. Knight DW, Sellin R (1987) The SERC flood channel facility. Water Environ J 1(2):198-204

31. Knight DW, Demetriou JD (1983) Flood plain and main channel flow interaction. J Hydraul Eng 109(8):1073-1092

32. Kouwen N, Fathi-Moghadam M (2000) Friction factors for coniferous trees along rivers. J Hydraul Eng 126(10):732-740

33. Macintosh, JC (1990) Hydraulic characteristics in channels of complex cross-section. Ph.D. dissertation, Univ. of Queensland

34. MacWilliams $M$, Tompkins $M$, Street $R$, Kondolf $G$, Kitanidis $P$ (2010) Assessment of the effectiveness of a constructed compound channel river restoration project on an incised stream. $J$ Hydraul Eng 136(12):1042-1052

35. Maidment DR (1993) Handbook of hydrology. McGraw-Hill, New York

36. Moreta PJM, Martin-Vide JP (2010) Apparent friction coefficient in straight compound channels. J Hydraul Res 48(2):169-177

37. Myers WR (1978) Momentum transfer in a compound channel. J Hydraul Res 16(2):139-150

38. Myers WR (1984) Frictional resistance in channels with floodplains, Proc. 1st Intl. Conf. Channels and Channel Control Structures, Computational Mechanics Centre, Heidelberg, Germany, 4.73-4.87

39. Naiman RJ, Fetherston KL, McKay S, Chen J (1998) Riparian forests. In: Naiman RJ, Bilby RE (eds) River ecology and management: lessons from the pacific coastal ecoregion. SpringerVerlag, New York, pp 289-323

40. Naot D, Nezu I, Nakagawa H (1993) Hydrodynamic behavior of compound rectangular open-channel flows. J Hydraul Eng 119(3):390-408

41. Nepf HM, Vivoni ER (2000) Flow structure in depth-limited, vegetated flow. J Geophys Res 105(12):28547-28557

42. Nezu I, Nakayama T (1997) Space-time correlation structures of horizontal coherent vortices in compound channel flows by using particle-tracking velocimetry. J Hydraul Res 35(2):191-208

43. Noutsopoulos G, Hadjipanos P. (1983) Discharge computations in compound channels. Proc. 20th Congress of the International Association for Hydraulic Research, Moscow, 5, 173-180

44. Ohl A, Tapsell S (2000) Flooding and human health - the dangers posed are not always obvious. BMJ 321:1167-1168

45. Pasche E, Rouvé $G$ (1985) Overbank flow with vegetatively roughened flood plains. J Hydraul Eng 111(9):1262-1278

46. Pradhan A, Khatua KK (2019) Discharge estimation at the apex of compound meandering channels. Water Resour Manage 33:3469-3483

47. Pradhan S, Khatua KK (2020) Momentum transfer coefficients at the adjoining interfaces of a compound channel. Flow Meas Instrum 75:101792. https://doi.org/10.1016/j.flowmeasinst. 2020.101792

48. Prinos P, Townsend RD (1984) Comparison of methods for predicting discharge in compound open channels. Adv Water Resour 7(12):180-187

49. Proust S (2005) Ecoulements non-uniformes en lits composés: effets de variations de largeur du lit majeur, PhD Thesis, INSA de Lyon, Lyon, France (in French)
50. Ruiz-Villanueva V, Molnar P (2020) Past, current, and future changes in floods in Switzerland. Hydro-CH2018 project. Commissioned by the Federal Office for the Environment (FOEN), Bern, Switzerland, $89 \mathrm{pp}$

51. Sanjou M, Nezu I (2011) Turbulence structure and concentration exchange property in compound open-channel flows with emergent trees on the floodplain edge. Int J River Basin Manag 9(3-4):181-193

52. Seckin G (2004) A comparison of one-dimensional Methods for estimating discharge capacity in straight compound channels. Can J Civ Eng 31(4):619-631

53. Sellin RHJ (1964) A laboratory investigation into the interaction between the flow in the channel of a river and that over its floodplain. La Houille Blanche 7:793-802

54. Singh P, Tang X (2020) Estimation of apparent shear stress of asymmetric compound channels using Neuro-Fuzzy Inference System. J Hydro-Environ Res 29(2):96-108

55. Singh $P$, Tang $X(2020)$ Zonal and overall discharge prediction using momentum exchange in smooth and rough asymmetric compound channel flows. J Irrig Drain Eng 146(9):1-13

56. Shiono K, Knight DW (1991) Turbulent open channel flows with variable depth across the channel. J Fluid Mech 222:617-646

57. Sun X, Shiono K (2009) Flow resistance of one-line emergent vegetation along the floodplain edge of a compound open channel. Adv Water Resour 32(3):430-438

58. Tang X (1999) Derivation of the wave speed-discharge relationship from cross section survey for use in approximate flood routing methods, PhD thesis, University of Birmingham, U.K.

59. Tang X, Knight DW (2009) Lateral distributions of streamwise velocity in compound channels with partially vegetated floodplains. J Sci China Ser E: Technol Sci 52(11):3357-3362

60. Tran HB, La Ngoc Q, Le Thi T, Tran TD, Debarati G (2011) Impacts of flood on health: epidemiologic evidence from Hanoi, Vietnam. Global Health Action 4:6356

61. van Prooijen BC, Battjes JA, Uijttewaal WSJ (2005) Momentum exchange in straight uniform compound channel flow. J Hydraul Eng 131(3):175-183

62. Vojoudi Mehrabani F, Mohammadi M, Ayyoubzadeh SA, Fernandes JN, Ferreira RML (2020) Turbulent flow structure in a vegetated non-prismatic compound channel. River Res Appl 36(9):1868-1878. https://doi.org/10.1002/rra.3723

63. Wormleaton P, Merrett D (1990) An improved method of calculation for steady uni-form flow in prismatic main channel/ floodplain sections. J Hydraul Res 28(2):157-174

64. Wormleaton PR, Allen J, Hadjipanos P (1982) Discharge assessment in com-pound channel flow. J Hydraul Div 108(9):975-994

65. Yagci O, Tschiesche U, Kabdasli MS (2010) The role of different forms of natural riparian vegetation on turbulence and kinetic energy characteristics. Adv Water Resour 33(5):601-614

66. Yang K, Cao S, Knight DW (2007) Flow patterns in compound channels with vegetated floodplains. J Hydraul Eng 133(2):148-159

Publisher's Note Springer Nature remains neutral with regard to jurisdictional claims in published maps and institutional affiliations. 